\title{
Empirical Application Of QQ Groupware In College English Teaching
}

\author{
Shuang Liu \\ College of Foreign Languages \\ Shenyang Aerospace University \\ Shenyang, 110136, China \\ E-mail: sy_orangedaisy@hotmail.com
}

\begin{abstract}
Presently computer networks interaction has become increasingly important in the interaction of teaching and learning. Most of the universities and colleges in China have accomplished the hardware construction of internet networks. But for some reasons, it is rather difficult to build up teaching interaction and conduct real teaching practice to implement and enhance the interactive networks teaching in the practice of college English teaching. Since QQ groupware can cater for the needs of a good language learning environment due to its popularity, convenience, low cost and other characteristics, QQ groupware may be helpful to construct the network environments of language learning. So from the year 2008 we have conducted an experiment in Shenyang Aerospace University on the role of QQ groupware in college English teaching. Our experiment is based on the constructivist theory and the theory of collaborative learning. From the analysis of QQ groupware functions, we tried to find out the positive roles that $Q Q$ groupware played in College English Teaching. And in the process of the experiment on the two sample classes in Grade 2008 and Grade 2010 of Shenyang Aerospace University, we explored the feasibility of $Q Q$ groupware in promoting college English teaching and proposed that QQ groupware play an active role in raising students' learning autonomy and improving students' language skills in English learning.
\end{abstract}

Keywords-Communicative Interaction; $Q Q$ Groupware; College English Teaching

\section{INTRODUCTION}

Nowadays with the ever rapid development and increasing popularity of the information technology, scientific and technological advances have tremendously changed all aspects of our society. College English teaching in China is therefore undergoing an unprecedented revolution.

In college English teaching, language teaching and learning activities should actually be the main interaction between the various interactive subjects in which teachers and students, students and students are in frequent and close contact. With the help of various practical and updated resources for teaching and learning, teachers have been looking for a variety of methods to develop students' English skills. Currently, most of the universities and colleges in China have accomplished the hardware construction of internet networks. But for some reasons, such as students' differences in English language acquisition, teachers' improper teaching strategies, students' poor learning autonomy etc., it is rather difficult to build up teaching interaction in real college English teaching practice. For a long time, language educators have clung to a transmission model, which sees the function of educational systems as the passing on of a received body of facts, values and procedures [1].

The ultimate goal of college English teaching is to train students in the practical application of language ability. Since QQ groupware can cater for the needs of a good language learning environment due to its popularity, convenience, low cost and other characteristics, QQ groupware may be helpful to construct the network environments of language learning. Through QQ groupware learning, students may be more interested in learning and they are likely to participate in learning actively, intensify learning through group discussion and improve their practical language skills. So from the year 2008 we conducted an experiment in Shenyang Aerospace University on the role of QQ groupware in college English teaching.

The research on the application of QQ groupware in teaching has attracted more attention in China since 2007, which mainly focuses on its application in developing distance education. Our experiment is based on the constructivist theory and the theory of collaborative learning. Through the analysis of QQ groupware functions, we try to find out the positive roles that QQ groupware played in College English Teaching. And in the process of the experiment on the two sample classes in Grade 2008 and Grade 2010 of Shenyang Aerospace University, we discuss the feasibility of QQ groupware in promoting college English teaching and propose that QQ groupware should play an active role in raising students' learning autonomy and improving students' language skills in English learning.

\section{The CONSTRUCtive TheORY AND COLlaborative LEARNING}

Constructivist teaching is based on constructivist learning theory. This theoretical framework holds that learning always builds upon knowledge that a student already knows; this prior knowledge is called a schema. Constructivists suggest that learning is more effective when a student is actively engaged in the learning process rather than attempting to receive knowledge passively. A wide variety of methods claim to be based on constructivist 
learning theory. Most of these methods rely on some form of guided discovery where the teacher avoids most direct instruction and attempts to lead the students through questions and activities to discover, discuss, appreciate and verbalize the new knowledge.

\section{A. Characteristics of a Constructivist Class}

One of the primary goals of constructivist teaching is that students learn by giving them the training to take initiative from their own learning experiences. According to Audrey Gray, the characteristics of a constructivist classroom are as follows: the learners are actively involved and the environment is democratic. The activities are interactive and student-centered and the teacher facilitates a process of learning in which students are encouraged to be responsible and autonomous.

\section{B. Characteristics of Collaborative Learning}

Collaborative learning is a situation in which two or more people learn or attempt to learn something together. ${ }^{[1]}$ Unlike individual learning, people engaged in collaborative learning capitalize on one another's resources and skills (asking one another for information, evaluating one another's ideas, monitoring one another's work, etc.). ${ }^{[2][3]}$ More specifically, collaborative learning is based on the model that knowledge can be created within a population where members actively interact by sharing experiences and take on asymmetry roles. ${ }^{[4]}$ Put differently, collaborative learning refers to methodologies and environments in which learners engage in a common task where each individual depends on and is accountable to each other. These include both face-to-face conversations ${ }^{[5]}$ and computer discussions (online forums, chat rooms, etc.). ${ }^{[6]}$ Methods for examining collaborative learning processes include conversation analysis and statistical discourse analysis. ${ }^{[7]}$

\section{Collaborative Learning Activities}

Collaborative learning is heavily rooted in Vygotsky's views that there exists an inherent social nature of learning which is shown through his theory of zone of proximal development. ${ }^{[8]}$ Often, collaborative learning is used as a term for a variety of approaches in education that involve joint intellectual effort by students or students and teachers. $^{[9]}$ Thus, collaborative learning is commonly illustrated when groups of students work together to search for understanding, meaning, or solutions or to create an artifact or product of their learning. Further, collaborative learning redefines traditional student-teacher relationship in the classroom which results in controversy over whether this paradigm is more beneficial than harmful. ${ }^{[10]}$ Collaborative learning activities can include collaborative writing, group projects, joint problem solving, debates, study teams and other activities. The approach is closely related to cooperative learning.

\section{FUNCTIONS OF QQ GROUPWARE}

QQ groupware can provide several means of different resources transmission and sharing for teachers and students.
A. Teachers and students can upload and download the files and share the information.

B. QQ group members can transmit the $Q Q$ files and share the files when the group members are online.

C. QQ group members can send and receive QQ group emails.

D. QQ groupware can utilize BBS to express ideas and store the document permanently, which can be convenient for the group members who are not online to browse.

QQ groupware photo album can make the members share the pictures and the volume limit is $10 \mathrm{M}$. The various kinds of resource share are very convenient for us to transmit the information and promote the teaching efficiency. In the same Group, the text or picture message sent by one member can be received by other group members. Compared with MSN or Skype, QQ Group can be created by QQ user directly without the help of any other software. Moreover, QQ Group is not a temporary group that would disappear when the conversation finished. On the contrary, once the QQ Group was created, it would be there even not any conversation happened. Even if someone in the group is not online when some group chatting happen, he also could get messages when he logged in QQ and know what had been talked in the group.

\section{EXPERIMENTAL PROCESS}

The experiment involved 120 English learners from Grade 2008 and Grade 2010 of College of Mechanical Engineering and College of Aerospace Engineering respectively in Shenyang Aerospace University. The students were expected to receive questionnaires and survey about their academic performance in statistics methods. Our textbooks are New Theme College English I and II (Intensive Reading and Listening).

\section{A. Questionnaires}

We designed two types of questionnaires. One is conducted before the project and the other is after the project. Our questionnaires are conducted by the on-site survey. We delivered 200 copies of questionnaires and got 200 copies back. All of the copies are effective. The first survey was conducted before the experiment to know the situation of students' using of QQ groupware, students' present spare time and practical use of English in class. The aim of the survey was to determine whether the application of QQ groupware will aid college English teaching or not. Another was conducted after the experiment to know the students' attitude and evaluation of the role the QQ groupware played in college English teaching.

\section{B. Experimental Process}

The experiment lasted for 14 weeks, which was divided into three stages: free talk stage (4 weeks); discussion stage (6 weeks) and autonomous study stage (4 weeks). Initially the teacher set up a QQ group for students from College of 
Mechanical Engineering and another one was made by the English representatives of students in College of Aerospace Engineering. The teacher served as the administrator. The students who wished to join QQ group should have the identity authentication. When the students joined in, they ought to provide their true names so that the teacher could write down their $\mathrm{QQ}$ numbers. In the free talk stage, we made the students use QQ group freely in order to see how students utilize QQ to solve questions. After 4 weeks, we found that for the first 2 weeks the students' involvement in discussion was rather active since QQ groupware is new to them. But after two weeks, students' enthusiasm became weak. They just made use of QQ group to deal with some related practical problems.

Mostly, in the process of the experiment, we served as the administrator to guide the students to study and promote the relationship between students. For example, some outstanding students were chosen by us to decide some topics for the students to discuss and the students were free to join in the group they preferred. Besides, the discussion result of each group would be required to upload to the BBS space group. Then the students of the class should evaluate the result of each group to form a second round of interaction. So QQ group can not only let the students create an active English learning situation outside class through this platform easily, but also merge their life experience into the language learning and promote the formation of language communication ability. In the second stage, the teacher served as an observer again not to provide any discussion topic but to involve in the discussion. The purpose is to test students whether they can practice collaborative learning independently. In the process, students needn't worry about their grammatical mistakes and incorrect expressions or consider the other students' better English level. Gradually students' practical English skills are improved through discussion. They try to express themselves freely in English after they get rid of their psychological barriers. Sometimes they will deal with the problems by online aid. The studying process is rather interesting and has better learning effects.

Since QQ groupware is very convenient, some useful files can be uploaded and download easily. Students were rather eager to share the information. They were motivated to learn more and upload more files on the platform.

\section{EXPERIMENTAL FINDINGS}

Some advantages of QQ groupware after conducting the experiment are found as follows.

\section{A. Super Simultaneous Interactive Capacity}

In the process of college English teaching, interaction is a very important section, which poses very high demand on the popularity and flexibility of the interactive medium.

\section{B. B. Big Volume of Interactive Membership}

An ordinary QQ groupware can have 100 memberships at most, which can satisfy the present teaching situation with more students in one class each time. In QQ groupware, students can communicate with each other simultaneously and equally, which not only can realize the aim of interaction from point to point, but also can make all the class students join in the group. According to the demand of discussion, we can even invite some of the other students outside the class to take part in the discussion topic temporarily.

\section{Wide extension of time and space}

QQ groupware can solve the problem of interactive group communication among different identities in different space. QQ groupware creates an English learning situation outside class and connects their own life experience into language learning thus promotes the language communication ability. QQ groupware is a dynamic virtual situation. It can make the whole teaching process flow into a real crash simulation of interaction in process. Students are stimulated by the creative passion and their enthusiasm in classroom participation is natural increased. Thus the students can learn simultaneously and flexibly.

\section{Great Pleasure of Entertainment and Popularity}

QQ groupware can exert its special effect of entertaining when discussion is somewhat boring since some students can get some interesting topics to modulate the atmosphere and promote the emotional communication among members, which is very helpful to proceed with the discussion.

Active roles of QQ groupware in English teaching and learning: promotion of teaching efficiency; cultivation of students' autonomy; strengthening of students' collaborative learning; emotional communication between teachers and students

Sending information by QQ groupware is a kind of bidirectional communication. QQ groupware will set up an open online class to discuss, collect and process information. Student's autonomy in learning English is cultivated from stage to stage. Initially students are passive in accepting information but after some time they get to know the changes if they can actively involve in the learning activities. Their study interest is greatly motivated by the pleasure they experience in learning. In the process of learning, two or more students need to communicate, cooperate and collaborate to accomplish the task of mastering the related English knowledge. Therefore students' collaborative learning are greatly strengthened. Discussions among teachers and students, students and students will be carried out in QQ groupware, which will provide more opportunity for students to express their own ideas and listen to the others. Students' learning motivation can be enhanced, thus making the language communicative competence can be improved. Both teachers and students can enjoy the pleasure of emotional communication between them.

\section{CONCLUSIONS}

After the experiment, we have come to the conclusions as follows: 


\section{A. A. Learning by QQ groupware is a bidirectional communication.}

QQ groupware will set up an open online class to discuss, collect and process information. Discussions among teachers and students, students and students will be carried out in QQ groupware, which will provide more opportunity for students to express their own idea and create a harmonious and relaxed atmosphere.

\section{B. Learning by QQ groupware can motivate the unity consciousness.}

QQ groupware can offer a platform to discuss problems, listen to the other's ideas which can make people feel as team members.

\section{Learning by QQ groupware can improve students' practical application skills.}

In the process of language study, QQ groupware can help students in many aspects and regard learning as something relaxing and cheerful, which can surely motivate self-learning and increase the learner's self-efficacy. Therefore, QQ groupware plays an active role in promoting college English teaching and raising students' learning autonomy and improving students' language skills in English learning.
[1] Chen, G., \& Chiu, M. M. (2008). Online discussion processes. Computers and Education, 50, 678 - 692.

[2] Chiu, M. M. (2000). Group problem solving processes: Social interactions and individual actions. Journal for the Theory of Social Behavior, 30, 1, 27-50. 600-631.

[3] Chiu, M. M. (2008). Flowing toward correct contributions during groups' mathematics problem solving: A statistical discourse analysis. Journal of the Learning Sciences, 17 (3), 415 - 463.

[4] Chiu, M. M., \& Khoo, L. (2005). A new method for analyzing sequential processes: Dynamic multi-level analysis. Small Group Research, 36, 600-631.

[5] Chiu, M. M. (2008). Effects of argumentation on group microcreativity. Contemporary Educational Psychology, 33, 383 - 402.

[6] Dillenbourg, P. (1999). Collaborative Learning: Cognitive and Computational Approaches. Advances in Learning and Instruction Series. New York, NY: Elsevier Science, Inc.

[7] Lee,C.D. and Smagorinsky, P. (Eds.).(2000). Vygotskian perspectives on literacy research: Constructing meaning through collaborative inquiry. Cambridge, England: Cambridge University Press.

[8] Mitnik, R., Recabarren, M., Nussbaum, M., \& Soto, A. (2009). Collaborative Robotic Instruction: A Graph Teaching Experience. Computers \& Education, 53(2), 330-342.

[9] Smith, B. L., \& MacGregor, J. T. (1992). "What Is Collaborative Learning?”. National Center on Postsecondary Teaching, Learning, and Assessment at Pennsylvania State University

[10] Y. J. Katz “Attitudes affecting college students' preferences for distance learning". Journal of Computer Assisted Learning.

\section{REFERENCES}

